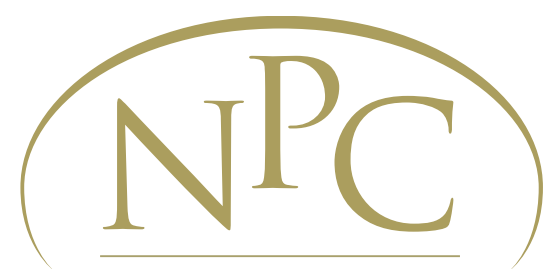

NATIONAL POVERTY

CENTER

National Poverty Center Working Paper Series

\#10-06

August 2010

\title{
Parental Job Loss and Children's Educational Attainment In Black and White Middle-Class Families
}

Ariel Kalil, University of Chicago and Patrick Wightman, University of Michigan

This paper is available online at the National Poverty Center Working Paper Series index at: http://www.npc.umich.edu/publications/working_papers/ 
Parental Job Loss and Children’s Educational Attainment in Black and White Middle-Class Families*

\author{
Ariel Kalil \\ University of Chicago \\ Patrick Wightman \\ University of Michigan
}

Forthcoming, Social Science Quarterly

*Direct all correspondence to Ariel Kalil, Harris Graduate School of Public Policy Studies, University of Chicago, 1155 East $60^{\text {th }}$ Street, Chicago, Illinois, 60637. E-mail: akalil@uchicago.edu.

Patrick Wightman will provide all data and coding information to those wishing to replicate the study.

This work was supported in part by a William T. Grant Foundation Faculty Scholars Award to the first author and a pre-doctoral fellowship from the Population Research Center at the University of Chicago to the second author. Support was also provided in part by funds provided to the National Poverty Center at the University of Michigan by the U.S. Department of Health and Human Services, Office of the Assistant Secretary for Planning and Evaluation,\#1 U01 AE000002-. Any opinions and conclusions expressed are solely those of the authors and should not be construed as representing the opinions or policy of any agency of the Federal government. We appreciate helpful comments from Greg Duncan, Tom DeLeire, Jens Ludwig, Bob Schoeni, Rob Fairlie, Dylan Conger and from seminar participants at the Population Research Center at the University of Chicago, the Department of Economics at the University of Stavanger, Norway, the School of Public Policy at the University of Toronto, and the La Follette School of Public Affairs at the University of Wisconsin. 


\title{
Parental Job Loss and Children’s Educational Attainment \\ in Black and White Middle-Class Families
}

\begin{abstract}

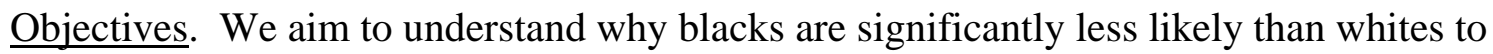
perpetuate their middle class status across generations. To do so, we focus on the potentially different associations between parental job loss and youth’s education al attainment in black and white middle class families.

Methods. We use data from the Panel Study of Income Dynamics (PSID), following those children "born” into the survey between 1968 and 1979 and followed through age 21. We conduct multivariate regression analyses to test the association between parental job loss during childhood and youth’s educational attainment by age 21 .

Results. We find that parental job loss is associated with a lesser likelihood of obtaining any post-secondary education for all offspring, but that the association for blacks is almost three times as strong. A substantial share of the differential impact of job loss on black and white middle class youth is explained by race differences in household wealth, long-run measures of family income, and, especially, parental experience of long-term unemployment.

Conclusions. These findings highlight the fragile economic foundation of the black middle-class and suggest that intergenerational persistence of class status in this population may be highly dependent on the avoidance of common economic shocks.
\end{abstract}




\section{Parental Job Loss and Children’s Educational Attainment in Black and White Middle-Class Families}

It is well-established that involuntary job loss and unemployment can lead to poorer future outcomes in the labor market (e.g., lower earnings) for the affected worker, significant material hardship, marital discord and divorce, and family stress and strained parent-child relations (Conger \& Elder, 1994; Farber, 1993; Jacobson, LaLonde, \& Sullivan, 1993; Rege, Telle, \& Votruba, 2008a; Ruhm, 1991; Stevens, 1997; Yeung \& Hofferth, 1998). Yet, relatively little is known about the long-run consequences of parental job loss for youth (but see Oreopolous, Page, \& Stevens, 2008 for a recent exception).

The present paper is focused on how parental job loss in middle-class households is associated with youth's educational attainment and, in particular, the experiences of black versus white middle-class households. This research question is motivated by the observation that although family income has risen for both blacks and whites over the past several decades, blacks are significantly less likely to perpetuate their middle class status across generations (Isaacs, 2008). One plausible explanation is that black and white families experience economic shocks, such as parental job loss, differently, even when they share the same class location. We contribute to this literature by investigating differences in the association between parental job loss and children's educational attainment using long-run data from the Panel Study of Income Dynamics (PSID). Doing so is important because it can provide insights into why blacks are less likely than whites to perpetuate their middle class status across generations.

Social scientists and policy makers alike should care about the determinants of youth’s educational attainment because, in today’s economy, a child’s educational attainment strongly influences his or her earnings. For instance, in 2007 those with just a high school degree had 
median weekly earnings of $\$ 604$ while the median weekly earnings of college graduates was \$987 (Bureau of Labor Statistics, 2008). However, on average, whites are more likely than blacks to graduate from high school (89.4\% and 80\%, respectively) and to hold a four-year college degree (30\% vs. $17.3 \%$, respectively). Our analysis will show that race gaps in educational attainment exist in the middle class as well.

To preview the results, we find that parental job loss is associated with a lesser likelihood of children's obtaining any post-secondary education and that the association for black middle class youth is almost three times as strong as for their white counterparts. A substantial share of the differential impact of job loss on black and white middle class youth is explained by race differences in household wealth, long-run measures of family income, and, especially, parental experience of long-term unemployment.

The remainder of the paper is organized as follows. Section 1 briefly reviews the existing literature on job loss and children’s educational attainment and motivates the investigation of race differences in the experience of parental job loss within the middle class. Section 2 describes our data and analytic method and Section 3 presents the results. Section 4 concludes.

\section{Background}

Parental job loss and children's educational attainment

A number of recent papers have illustrated the deleterious impacts of parental job loss on children’s educational achievement and attainment (Kalil \& Ziol-Guest, 2008; Kertesi \& Kezdi, 2007; Rege, Telle, \& Votruba, 2008b) as well as on children’s long-run human capital development (Oreopoulos et al., 2008). Involuntary job losses may adversely affect children’s educational attainment for a number of reasons. First, job losses lead to unemployment and income losses for the affected worker (Farber, 1997; Jacobson, LaLonde, \& Sullivan, 1993; 
Ruhm, 1991) and this can limit the income necessary to purchase such things as education and cognitively enriched learning environments that are important for children's educational achievement and attainment (Becker \& Thomes, 1986; Carneiro and Heckman, 2003; Duncan \& Brooks-Gunn, 1997; Dynarski, 2003; Yeung, Linver \& Brooks-Gunn, 2002).

Second, involuntary job losses are also presumed to be psychologically stressful for parents (see Conger \& Elder, 1994; McLoyd, Jayaratne, Ceballo, \& Borquez, 1994; Rege et al., 2008a). These family pressures can inhibit parents' emotional warmth and increase parents' erratic or disengaged behaviors. In turn, ineffective parenting can lead to children's poorer performance in school (Elder, Nguyen, \& Caspi, 1985; McLoyd, 1998). Third, children’s achievement motivation and school engagement could be directly affected by their parents' job loss (Galambos \& Silbereisen, 1987). For example, Barling, Zacharatos, and Hepburn (1999) showed that undergraduates who perceive their parents to be insecure about their jobs are distracted cognitively and have worse academic performance.

Race differences in the consequences of parental job loss

Recent evidence suggests that blacks are significantly less likely than whites to perpetuate their middle class status across generations. In a new analysis of data from the PSID, Isaacs (2008) reported that $45 \%$ of black children who grew up in middle class households ended up in the bottom quintile of the earnings distribution as adults. In contrast, only $16 \%$ of whites experienced similar downward mobility. Although there are a variety of reasons that could explain these phenomena, one plausible explanation is that black and white middle class families respond differently to economic events that occur over the course of children's development. In this paper, we examine whether the impacts of a relatively common economic event - parental job loss - differ across the two populations. 
There are a variety of factors that could make the job loss experience different for black and white middle class families. First, some evidence suggests that within the middle class, exposure to and consequences of job loss are more severe for blacks. Wilson, Tienda, and Wu (1995) find that among college graduates, blacks are 2.24 times as likely to be dismissed or laid off as whites, whereas Spalter-Roth and Deitch (1999) report that blacks who lose jobs are more likely than their white counterparts to fall from professional or managerial to lower level and less well-remunerated occupations.

Second, well-documented differences in black and white wealth in the middle class might also make the job loss experience different for families in these two groups. Race differences in wealth far exceed race differences in income, occupational, and educational levels; this difference is especially pronounced among the middle class (Conley, 1999; Oliver \& Shapiro, 1997; Pattillo-McCoy, 1999).

Wealth can affect a family's ability to sustain itself through a job loss. Financial assets, which can be liquidated or against which families can borrow, can mitigate the negative effects of a parental job loss by alleviating economic pressure and serving as a "psychological buffer" against worries about the future. Parents in families with few assets or little equity to draw upon may be particularly pessimistic about their children's future in the event of a household economic downturn. The transmission of these beliefs and expectations may affect the youth's own expectations and behaviors. Similarly, adolescents' reactions to parental employment downturns may be moderated by the knowledge that vital financial resources are available from sources other than parents' current earnings. This may be especially important during adolescence, when families are making plans for children's college attendance and how to finance it. 
In sum, there are reasons to expect that parental job loss may have differential associations with youth's educational attainment in black and white households among the middle class. We hypothesize that parental job loss may be associated with more adverse outcomes for black youth. We explore the possible mechanisms accounting for this phenomenon by examining whether middle-class race differences in long-run income, long-term unemployment, and wealth account for middle-class race differences in the impact of parental job loss on children’s educational attainment.

\section{Method}

\section{Sample Description and Measures}

We use the Panel Study of Income Dynamics for our analysis. The PSID is a longitudinal survey consisting of individuals (men, women, and children) and the families in which they reside (http://psidonline.isr.umich.edu). It is the longest-running longitudinal study of household income in the United States and collects detailed economic and demographic information over the life course. Since 1968, the PSID has tracked, interviewed, and disseminated data from a nationally representative sample of approximately 5,000 US households. Annually from 1968 to 1996 and biennially from 1997 to 2005, all members of the original households in the study, regardless of whether they were living in the same dwelling or with the same people, were tracked in the study. Thus, children born into study families, who themselves constituted representative birth cohorts (Duncan \& Hill, 1985) were surveyed as they advanced through childhood and into adulthood. Despite attrition (the effects of which appear to be captured in weighting adjustments; see Fitzgerald, Gottschalk, \& Moffitt, 1998) and the challenges of following offspring as they formed their own households, the sample size grew 
from 4800 families in 1968 to 7435 families in 2005. All respondents were compensated for their time.

Because the original focus of the data collection effort was the dynamics of poverty, the PSID was initially comprises of two independent samples, a cross-sectional national sample and a supplemental sample of households located in census enumeration districts with large nonwhite populations (the Census Survey of Economic Opportunity [SEO] sample). The oversampling of families in non-white neighborhoods in the late 1960s resulted in a sizable subsample of African American families (of the original 4802 families, 33\% were African American). Because of the sampling strategy, we use the survey-supplied probability-ofselection weights, which correct for unequal selection probabilities as well as differential attrition, in all our analyses. The application of these weights generates a sample that is representative of the U.S. non-immigrant population. Specifically, we use the weight associated with the survey year each offspring's educational attainment was measured.

To construct the sample we start with the pooled cross section of individuals who are "born” into the survey, that is, observed at age one and subsequently followed through age 21. We rely on total family income around the time of the child's birth to determine class status, given that any measure of income derived over the course of the offspring's childhood (defined as ages 0-17) is likely endogenous to parental job loss. Because single-year income measures are less representative of permanent income, we average over one or two years prior to the offspring's birth year. The choice of the number of years used to generate this number for each household depends on data availability; i.e.,, the household's survey participation (we only know birth-year income for sample offspring born in 1968) and family formation (the number of years prior to the offspring's birth year that his or her parents began their own household). The 
average number of years used to generate this "initial income” measure is 2.5 for both blacks and whites-70\% of both whites and blacks contributed three years' worth of income data to this measure.

Following Duncan, Smeeding, and Rodgers (1992) we designate as “middle-class” those offspring born into households whose initial income is between two and six times the appropriate poverty threshold (i.e. adjusted for family size and age of household head). In 2005, for a family of four this range extends from $\$ 38,700$ to $\$ 116,10{ }^{1}$ All monetary units have been adjusted to 2005 real levels using the Consumer Price Index (CPI). Figure 1 shows the average income (in \$1,000’s) for black and white middle class families at each decile of their respective distributions. These criteria generate a final (unweighted) sample of 1,374 offspring born into middle class households: 1,097 whites and 277 blacks. These births represent $63 \%$ of white births and 22\% of black births across the 13 cohorts from which they are drawn. (By way of contrast, $30 \%$ of white births and $77 \%$ of black births in the PSID during these years are to families with initial incomes below $200 \%$ of the poverty line.)

Our dependent variable is the report of any post-secondary education by the age of twenty-one (more specifically, the offspring's twenty-first survey year). Because individual information varies by the relationship to the household head (the male spouse in two- parent households, by convention), we use three sources to construct a measure of education that is consistent and uniform and also maximizes the potential sample. For offspring still residing in their parents' households, the measure is the number of years of completed schooling; those who

\footnotetext{
${ }^{1}$ We conducted sensitivity analyses by narrowing this range on the lower and upper end. Raising the lower threshold to three times the poverty standard left too few households for analysis. Lowering the upper threshold to four times the poverty standard had no appreciable impact on our overall results, but decreased the sample size. Indeed, comparing the black and white income distributions within our preferred range indicates that the means and dispersions are largely the same (see Figure 1). This suggests that, at least along this dimension, the black and white households comprising our preferred sample are properly matched.
} 
report thirteen or more years of completed education are categorized as college entrants.

Offspring who reside in academic institutions are also counted as college entrants. For offspring who are heads and spouses of their own households by twenty-one, we count as post-secondary education any report of either non-academic training, some college but no degree, or a college degree. Of those children born into middle-class households, $61 \%$ of whites and $52 \%$ of blacks report some post-secondary education by age twenty-one (this difference is statistically significant at the 10 percent level). ${ }^{2}$

Admittedly, this method obscures variation in the post-secondary educational opportunities available to young adults. The measure employed here could represent a mixture of attainment ranging from a single term at a two-year community college to early completion of a four-year undergraduate degree. Unfortunately detail at this level is only reported for heads and spouses. Of the middle-class sample, only $25 \%$ of white offspring and $13 \%$ of black offspring are either the head or spouse of an independent household by age 21, samples that are prohibitively small. ${ }^{3}$ Nevertheless our outcome measure is a meaningful indicator of adult success: the $52 \%$ post-secondary education rate among black offspring born into middle-class households is nearly 20 percentage points higher than the overall rate for black children born into the PSID. Furthermore using the full PSID, respondents who, by age 21, met the post-secondary education requirements described above report \$6,000 more in income at age 25 compared to high school graduates with no post-secondary education, and more than $\$ 20,000$ more in income compared to respondents who failed to complete high school.

\footnotetext{
2 This measure is missing for five offspring — all white-born into the middle-class households who are subsequently dropped from the analysis. Other than this missing values do not pose any threat to our analyses.

${ }^{3}$ Whites are more likely to be heads or spouses in their own households by age twenty-one, otherwise there is no significant difference in the source of information between blacks and whites
} 
We consider jobs lost by household heads. Following Ruhm (1991), Stevens (1997), and Stephens (2002) the job losers in our sample are those parents who report being involuntarily separated from their employment as a result of either a plant closing/employer death or lay off/dismissal. Using this definition, $40 \%$ of the whites and $46 \%$ of the blacks in our middle class sample grew up in a household in which a parent lost a job at some point, a difference which is not statistically significant. ${ }^{4}$

There may be reason to be concern that being dismissed (i.e., fired) is fundamentally different than losing a job because of a plant closing or downsizing. For example, when an individual is fired, he or she is likely being singled out for incompetence or bad behavior. Personal attributes that put an individual at risk of being fired may be correlated with parenting behaviors, potentially biasing the estimated association between job loss and children’s outcomes. While we cannot, in practice, we cannot distinguish firings from lay-offs, a number of considerations lead us to proceed using this measure. First, in their study of job loss in the PSID, Boisjoly, Duncan \& Smeeding (1998) report that only 16\% of the lay-offs/dismissals reported between 1968 and 1992 were actual firings. Thus, on average, the bias that may result from the inclusion of individuals who were fired, while non-trivial, is likely to be minimal. ${ }^{5}$ Second, inasmuch as being fired typically results in the loss of employment and earnings, along with other consequences of job loss, it is not clear a priori that parents who were fired should be excluded from our sample. Third, our main interest is not in the effects of the job loss per se, but rather the difference in the effects of job loss in black versus white families.

\footnotetext{
${ }^{4}$ We drop offspring whose parents reported a job loss in the 1968 wave of the PSID, as the recall period associated with the question in this wave extends beyond the previous year. Including these individuals does not change the results presented below.

${ }^{5}$ Unfortunately, Boisjoly et. al. did not report whether the share of fires in the lay-offs/dismissal category differed by race.
} 
Ultimately, it is important to consider the potential for unobserved factors influencing selection (first into the sample and then into job loss) together. If, for example, the black households we observe are positively selected into the middle class (relative to their white counterparts), one might expect any adverse impact of parental job loss on children’s educational attainment to be dampened by those same (unobserved) factors responsible for selecting the black parent generation into the middle class. In this the case, our results would in fact be a conservative estimate of the impact of parental job loss on black middle class youth's outcomes. Analysis Plan

The analysis proceeds as follows: we first estimate the effect of job loss on the entire sample of offspring born to PSID households. We next add indicators for initial class status (middle- and high-income, low-income status is the reference category) to see the household's income level mediates the average job-loss effect. We then interact the status indicators and the job-loss variable with indicators for the offspring's race to determine if race has a moderating effect. Our final specification using the entire sample incorporates a set of triple interactions, race $\mathrm{x}$ class status $\mathrm{x}$ job loss, to examine whether race moderates the job-loss effect within the indicated SES levels.

We then turn our focus to the middle class sample. In these models the controls are fully interacted with the race indicators in order to create a framework that is more flexible in its treatment of differences between black and white households. These models are then expanded to include three measures of economic conditions that prevailed over the course of the offspring's childhood, in order to explore the mechanisms connecting job loss and children’s outcomes and potential differences in these mechanisms by race. The three variables we focus on here are 1) average annual family income from age 1 to 17 (in 2005 dollars); 2) the number of 
years over the offspring's childhood that he or she lived in an owned home (compared to a rented home; this is our proxy measure of wealth); and 3) whether the head of household ever experienced a period of unemployment of six months or more within a single year (a spell of “long-term unemployment”).

The results presented here were generated using ordinary least squares. Consequently, the coefficient estimates measure the percentage-point change in the probability of obtaining any post-secondary education attributable to a one-unit change in the corresponding independent variable. We present these results instead of those generated by non-linear estimation methods for the sake of ease of interpretation, in particular because interpreting interaction effects within a non-linear framework is somewhat cumbersome. Furthermore, the rates of the job loss (41 percent) and attainment of post-secondary education (60 percent) fall well within the range over which the advantages of nonlinear estimation are muted. Nevertheless we conducted all of the analyses using probit models and the coefficients generated by these methods are qualitatively and quantitatively very similar, as one would expect. All standard errors are estimated using the Huber-White variance-covariance estimator, as well as a correction for clustering which may arise due to the fact that some of the offspring in our sample come from the same households. ${ }^{6}$

\section{Results}

Means and standard deviations of these variables are reported in Table 1. For the sake of comparison the first three columns present the descriptive statistics for the sample of all children born into the PSID and observed through age 21; these numbers are reported for the middle class sample in the second three columns of coefficients. As can be seen, while there are significant racial differences in the total sample, these differences are much smaller in the middle class

\footnotetext{
${ }^{6}$ This is accomplished by first summing the square of the product of the residuals and the covariate vectors within clusters (families) and then adding these sums across clusters.
} 
sample — evidence that our measure of class status captures important distinctions beyond differences in income.

Insert Table 1 about here

Within the middle class sample, the initial income of white and black offspring is $\$ 57,279$ and $\$ 53,334$, respectively, a difference that is statistically significant. However, in contrast, in the full sample, average initial income among blacks and whites differs by over $\$ 20,00$. Moreover, Figure 1 shows that the black and white distributions of initial income within our middle-class definition are similar, and this provides reassurance that we are not simply comparing white offspring born into the upper end of the middle-class income range to black offspring born into the lower end.

Demographic controls include the individual's gender (female coded as 1), birth order (dummy variable equal to 1 if firstborn), the number of additional siblings in the household at the time of the offspring's birth, an indicator for whether at least one parent has a college degree, a dummy variable indicating that the individual was born into a two-parent household, dummy variables for the region of birth (Northeast, North Central and West, the South is the reference category $^{7}$ ), the measure of initial income and a battery of dummy variables for the offspring's birth year. Sample, or survey controls include dummy variables for each of the following conditions: if fewer than three years were used to determine initial income, if the individual recorded one or more survey non-response between ages 1 and 17 (we assume that such nonresponses are random) and if the offspring's originating 1968 household was part of the Census SEO sample. ${ }^{8}$

\footnotetext{
${ }^{7}$ The omitted category also includes less than one percent of the white offspring in our sample who were born outside the continental U.S.

${ }^{8}$ This includes the children of second generation PSID respondents whose original households were part of the SEO sample.
} 


\section{Multivariate Results}

Table 2 shows the results from using the sample of all offspring born into the PSID and a series of specifications in which job loss, class status, and race are successively interacted, as described earlier.

Insert Table 2 about here

As seen in column (1), parental job loss is associated with a 10 percentage point reduction in the probability that the offspring obtains any post-secondary education, an effect size of nearly 20 percent. Adding controls for initial class status in column (2) does not affect this result. However, relative to being born into a low income family, being born into the middle class more than offsets the negative job-loss effect. The specification reported in column (3) interacts the black indicator with each of the job loss and initial class status indicators. ${ }^{9}$ In each case black offspring attain less education than their white counterparts but the interaction is never significant. The last specification, reported in column (4), interacts class status with both job loss and the race indicator and all three together. As can be seen, for black offspring born into middle-class households the likelihood of any obtaining any post-secondary education is reduced by 16 percentage points (significant at the 17 percent level) if their parents report losing a job—25 percentage points when taking the main effect into account.

A subsequent series of Chow tests indicate statistically significant structural differences between both the middle-class sample and the low- and high-income samples, and—within the middle-class designation—statistically significant, structural differences between black and white offspring.

Chow Tests of Structural Differences

\begin{tabular}{l|l|l} 
Middle vs & Middle vs & Blacks and Whites
\end{tabular}

\footnotetext{
${ }^{9}$ Only five black offspring were born into high income households.
} 


\begin{tabular}{|c|c|c|c|c|}
\cline { 2 - 3 } \multicolumn{1}{c|}{} & & & Full Sample & Middle Class \\
\hline F-statistic & 2.9604 & 1.3651 & 4.9330 & 2.5793 \\
\hline P-value & 0.0007 & 0.1669 & 0.0000 & 0.0023 \\
\hline
\end{tabular}

These findings, together with the patterns shown in Table 2, motivate our analytical focus on the middle-class sample using fully-interacted (with respect to race) models.

Our main results are reported in Table 3. Columns (1) and (2) report the point estimates from a fully interacted model in which the common constant is suppressed and replaced with separate black and white indicators. Column (3) reports the results of post-hoc F-tests on the equivalence of the black and white point estimates. The differences reported in Column (3) are identical to the coefficient estimates we would obtain were we to instead estimate these models with a black indicator interacted with each of the covariates. We use the specification described above in order to provide a descriptively more accessible picture of both the impact of and the differential impact of job loss in black and white middle class families.

Insert Table 3 about here

As can be seen, parental job loss decreases the probability of entering college for both black and white middle class children. For white middle class children, parental job loss reduces this likelihood by approximately 9 percentage points. For black middle class children the impact is -25 percentage points, a statistically significant effect size of 50\%. This black-white gap is statistically significant at the 10 percent level. Among the background characteristics, the benefit to having at least one college-educated parent is greater for blacks, as is being born into a two-parent household. Overall, females are more likely to enter college, whereas firstborns are less likely. Within the range of middle-class initial income, initial income (in 10,000 of dollars) is positively associated with white offspring's college attendance whereas the association among black offspring is statistically insignificant. 


\section{Mediating Role of Childhood Conditions}

The specifications in Table 4 expand the set of controls to include measures of the economic conditions and parents' labor market experiences that prevailed over the offspring's childhood. Although within this sample our black and white populations are comparable at birth in terms of household income and, for the most part, family structure, a review of Table 1 shows that these two populations experience very different economic conditions during their offspring's childhood. Although the difference in the rate of job loss in the two populations is not statistically significant, average family income over the course of the offspring's childhood and adolescence is significantly lower in the black population: $\$ 53,286$ versus $\$ 72,519$ among whites. This divergence is primarily due to the fact that among the black offspring in our sample, the growth of household annual income is stagnant, whereas among the white offspring it is steadily increasing ${ }^{10}$. Figure 2 illustrates these trends.

Black children born into middle class households spend almost four fewer years in a home that is owned, and black household heads are more than twice as likely (32\% versus $15 \%)$ to report 6 months or more of unemployment within a single year, compared to their white counterparts. Furthermore, regressing these measures against parental job loss and the other baseline controls (results not reported) suggests that the associations between the job loss and these economic conditions are substantially larger among blacks than whites, especially for the long-run unemployment measure.

\footnotetext{
${ }^{10}$ A comparison of the distribution of average annual income by race indicates that this divergence is due in part to the right tail of the white distribution. The maximum mean annual income among blacks is just under $\$ 143,000$, while for whites the maximum is approximately $\$ 52,000$. To examine the importance of this divergence we trimmed the outliers on the upper end and re-estimated the models on the sample of offspring whose average childhood income fell within our middle class designation, i.e. 2-6 times the poverty threshold. The results were similar.
} 
These variables are designed to serve as proxies of the resources available to offspring as they grow up. It is important to note that because these conditions are measured over the entire childhood they do not take into account the timing of the job loss and therefore do not constitute mediation tests in the formal sense. Nevertheless, if the effect of job loss is diminished by the addition of one or more of these controls, we may reasonably assume that the relationship between parental job loss and children's educational attainment operates at least in part through one or more of these intermediary channels. Some evidence supporting this claim is found in separate models (results available upon request) which show job loss to be strongly predictive of each of these measures.

\section{Insert Table 4 about here}

The first specification in Table 4 adds the measures of average annual income (in tenthousands of dollars) and the number of years in an owned home. Average annual income gives some indication of the liquid resources available to a household at any given time, while owned homes are the primary repository of non-liquid wealth in America. As can be seen in the first three columns, the inclusion of these two variables has a moderate impact on the magnitude and differential impact of parental job loss. For example, the percentage point impact of job loss on college-going in the black population drops from -25 to -21, a decrease of about 20\%. Likewise, the differential impact drops from 17 to 14 percentage points. Average family income is positively associated with college-going for blacks and whites, whereas years in an owned home is not. Additional wealth measures we examined included average home value and receipt of asset, dividend or rental income. These measures were not predictive of educational attainment and they “mediated” neither the relationship between parental job loss and educational attainment nor the black-white differential. 
The second specification examines the role of long-run unemployment. Recall that $32 \%$ of the black offspring in our sample had a parent report at least six months of unemployment within a year, more than double the rate among white offspring. This variable exhibits the same effects as the job loss variable: six months of unemployment within a single year significantly reduces the likelihood of college attendance among both whites and blacks but the impact on black offspring is three times the magnitude of the impact on their white counterparts. Moreover, controlling for long unemployment spells, the impact of job loss on college attendance among blacks is about 10 percentage points smaller (in absolute terms) and the middle-class black-white gap, while still sizable at 7 percentage points, is reduced by over $50 \%$ (and is no longer statistically significant at conventional levels). This suggests that a significant portion of the black-white differential in the impact of job loss likely results from the greater labor market problems experienced by black middle-class households following a job loss. ${ }^{11}$ When we estimated a model that includes all of these conditions together we reach similar conclusions (columns 7-9).

We also examined other childhood economic conditions that are potentially correlated with parental job loss. These included the number of residential relocations, the number of years the family income was below our middle-class designation, the number of years the family's income fell below the official poverty threshold, and the number of years the offspring resided with a single parent. In each case black middle class offspring fare less well than their white counterparts and in each case the association with offspring's post-secondary education was negative. However, none of these additional variables significantly affected (i.e., mediated) the estimated job loss effects, either separately or together, in regression models.

\footnotetext{
${ }^{11}$ Setting aside the inability to control for the sequence of events, a Sobel test for mediation on the long-run unemployment measure is statistically significant at the 1 percent level and also indicates that this variable explains nearly 86 percent of the total effect among black offspring.
} 


\section{Conclusion}

As Jencks (1972) once wrote “Inequality is recreated anew in each generation, even among those who start life in essentially identical circumstances.” The legacy of race, as a key determinant of attainment, also persists, even in the middle class. Here, we have identified one possible reason why this might be the case: among middle class families, parents' involuntary job loss is associated with lesser educational attainment to a significantly greater extent among blacks than among whites. These findings are important given the central role played by education in future earnings. Moreover, these findings underscore the ways in which middle class blacks and whites do not start (or experience) life in "essentially identical circumstances” despite their similarity on a number of key dimensions, including family income at the "starting gate.”

The relatively small sample we have available to investigate this question does not allow us to push these findings much further. It bears repeating that we have a sample of only 277 middle-class blacks. At best, we have identified race differences in the reduced-form association between parental job loss and children's educational attainment. Nonetheless, our data provide some hints that the economically destabilizing effect of a job loss is greater for blacks than whites in middle class households and that these factors play a mediating role.

As we showed, middle class black households in our data are more likely to experience spells of long-term unemployment and there is a stronger correlation between job loss and longterm unemployment for blacks than for whites. Long-run unemployment, like job loss, is also more strongly correlated with educational attainment for blacks than for whites. In our regressions, a substantial share of the differential impact of job loss on black and white middle class youth is explained by the group of measures representing race differences in household 
wealth, long-run measures of family income, and parental experience of long-term unemployment. These findings underscore the race differences in middle class wealth and economic security reported elsewhere (Conley, 1999; Oliver \& Shapiro, 1997).

The partial mediating role of economic conditions could indicate that parents lack the resources to invest in their children's education at an early age, with consequences for children's later attainment, or it could be that parents' lack of resources diminishes youth's expectations that college-going will be an opportunity they can take advantage of. It could also be that parents who experience long-run unemployment convey their own pessimism about the labor market to their children, which has implications for how long youth persist in school.

It is interesting that the single measure of parental long-run unemployment played a greater mediating role than the joint contribution of long-run income and wealth as mediators. It is possible that impacts on children do not arise purely via economic channels but rather through the potentially adverse psychological consequences, perhaps as expressed in parental depression, marital conflict or children's behavior problems, that could result from parents' long-run unemployment.

One might reasonably ask whether we have simply identified differences in the impact of an economic shock such as job loss in populations who differ along key economic dimensions such as wealth, and, consequently, whether our findings would have been the same had we compared, say, low-wealth middle class whites to higher-wealth middle class whites. In response, we focus on our finding that most (80\%) of the "race gap" in the impact of job loss is not explained by our two indicators of childhood economic status (i.e., childhood income and wealth). This suggests that some of the differential response to job loss in black and white middle class families could be due to factors that are specific to race. Such factors could include 
the different ways in which the job loss event is interpreted within families or the psychological aspects of how job losers and their children make meaning out of and respond to these experiences. Future work could build on the findings we have reported here by measuring and testing these alternative possible mechanisms.

In sum, our findings highlight the fragile economic foundation of the black middle-class. Intergenerational persistence of class status in this population may be highly dependent on the avoidance of common economic shocks. Our study thus raises important questions about the continuing ability of all Americans to transfer a secure economic position to future generations, and calls for greater scientific energy to be devoted to understanding this phenomenon. Policies that help increase black families’ economic security may be important in helping pave the way for future generations of black youth to achieve socioeconomic success. 


\section{References}

Barling, J., Zacharatos, A., \& Hepburn, C. (1999). Parents’ job insecurity affects children’s academic performance through cognitive difficulties. Journal of Applied Psychology, 84, 437-444.

Becker, G. S., \& Thomes, N. (1986). Human capital and the rise and fall in families. Journal of Labor Economics, 4, S1-S139.

Boisjoly, J., G. Duncan and T. Smeeding (1998) “The Shifting Incidence of Involuntary Job Losses from 1968 to 1992.” Industrial Relations 37(2), April, 207-231.

Bureau of Labor Statistics, Current Population Survey (2008, April 15). Available at www.bls.gov/

Carneiro, P \& Heckman, J. (2003). “Human Capital Policy” in J. Heckman \& A. Krueger (Eds.), Inequality in America: What Role for Human Capital Policies? (pp. 77-240). Cambridge, MA: MIT Press.

Conger, R.D. \& Elder, G. (1994). Families in troubled times. New York: Aldine de Gruyter.

Conley, D. (1999), Being Black, Living in the Red: Race, Wealth, and Social Policy in America. University of California Press.

Duncan, G. \& Brooks-Gunn, J. (1997). Consequences of Growing up Poor. New York: Russell Sage Foundation.

Duncan, G. \& Hill, MS. (1985). Conceptions of longitudinal households: fertile or futile? J Econ Soc Meas. 13:361-375.

Duncan, G., T. Smeeding \& W. Rodgers (1992) "The Incredible Shrinking Middle Class," American Demographics, Vol. 14, No. 5, pp. 34-38. 
Dynarski, S. (2003), "Does Aid Matter? Measuring the Effect of Student Aid on College Attendance and Completion”, The American Economic Review, 93(1), 279-288.

Elder, G.H. (1998). The life course as developmental theory. Child Development 69, 1-12.

Elder, G.H., Nguyen, T., \& Caspi, A. (1985). Linking family hardship to children’s lives. Child Development, 56, 361-375.

Farber, H.S. (1993). The incidence and costs of job loss: 1982-91. Brookings Papers: Microeconomics 1993, 73-119.

Farber, H.S. (1997). The changing face of job loss in the United States. Brookings Papers: Microeconomics 1997, 55-142.

Fitzgerald J, Gottschalk P, Moffitt R. (1998). An analysis of sample attrition in panel data: the Michigan Panel Study of Income Dynamics. Journal of Human Resources. 33; 155-184.

Galambos, N. \& Silbereisen, R. (1987). Income change, parental life outlook, and adolescent expectations for job success. Journal of Marriage and the Family, 49, 141-149.

Hertz, T. (2003). Rags, riches, and race: The intergenerational economic mobility of black and white families in the United States. In Bowles, S., Gintis, H., \& Osborne, M. (Eds.), Unequal chances: Family background and Economic Success. New York: Russell Sage. Issacs, J. (2008). “Economic mobility of black and white families.” In J. Isaacs, I. Sawhill, \& R. Haskins. Getting Ahead or Losing Ground: Economic Mobility in America. Washington, D.C.: Economic mobility project, and initiative of the Pew Charitable Trusts. Available at: http://www.economicmobility.org/assets/pdfs/EMP_BlackandWhite_ChapterVI.pdf

Jacobson, L., R. LaLonde and D. Sullivan (1993), “Earnings Losses of Displaced Workers”, The American Economic Review, 83(4), 685-709. 
Jencks, C. (1972). Inequality: A reassessment of the effect of family and schooling in America. New York: Basic Books.

Kalil, A. \& Ziol-Guest, K. (2008). Parental job loss and children's academic progress in twoparent families. Social Science Research, 37, 500-515.

Kane, T. (2001), “College-Going and Inequality: A Literature Review”, New York: Russell Sage Foundation.

Kertesi, Gabor and Kezdi, Gabor (2007) "Children of the Post-Communist Transition: Age at the Time of the Parents' Job Loss and Dropping Out of Secondary School," The B.E. Journal of Economic Analysis \& Policy: Vol. 7 : Iss. 2 (Contributions), Article 8.

MacLeod, J. (1995). Ain’t no makin’ it. Boulder, CO: Westview Press.

McLoyd, V. (1998). Socioeconomic disadvantage and child development. American Psychologist, 53, 185-204.

McLoyd, V., Jayaratne, T., Ceballo, R., \& Borquez, J. (1994). Unemployment and work interruption among African American single mothers: Effects on parenting and adolescent socioemotional functioning. Child Development, 65, 562-589.

Oliver, M. \& Shapiro, T. (1997). Black Wealth, White Wealth: A New Perspective on Racial Inequality. New York: Routledge.

Oreopoulos, P., M. Page and A. Stevens (2008) The Intergenerational Effect of Worker Displacement. Journal of Labor Economics, 26 (3), 455-50.

Pattillo-McCoy, M. (1999). Black picket fences. Chicago: University of Chicago Press. Rege, M.; Telle, K., \& Votruba, M. (2008a). Job loss and marital dissolution. Unpublished manuscript, University of Stavanger, Norway. 
Rege, M.; Telle, K., \& Votruba, M. (2008b). Parental job loss and children's school performance. Unpublished manuscript, University of Stavanger, Norway.

Ruhm, C. (1991), “Are Workers Permanently Scarred by Job Displacements?”, The American Economic Review, March, 319-324.

Spalter-Roth, R. \& Deitch, C. (1999). “I don’t feel right sized; I feel out-of-work sized.” Work and Occupations, 26, 446-483.

Stephens Jr., M. (2002), “Worker Displacement and the Added Worker Effect”, Journal of Labor Economics, 20(3), 504-537.

Stevens, A. (1997), “Persistent Effects of Job Displacement: The Importance of Multiple Job Losses”, Journal of Labor Economics, 15(1), 165-188.

Taylor, R., Casten, R., Flickinger, S., Roberts, D., \& Fulmore, C. (1994). Explaining the school performance of African-American adolescents. Journal of Research on Adolescence, 4, 21-44.

Wilson, F., Tienda, M., \& Wu, L. (1995). Race and unemployment: Labor market experiences of black and white men, 1968-1988. Work and Occupations, 22, 245-27.

Yeung, W. and S. Hofferth (1998), "Family Adaptations to Income and Job Loss in the U.S.”, Journal of Family and Economic Issues, 19(3), 255-283.

Yeung, W., M. Linver, and J. Brooks-Gunn (2002), “How Money Matters for Young Children’s Development: Parental Investment and Family Processes”, Child Development, 73(6), 1861-1879. 
TABLE 1

Descriptive Statistics

\begin{tabular}{|c|c|c|c|c|c|c|}
\hline & \multicolumn{3}{|c|}{ Full Sample } & \multicolumn{3}{|c|}{ Middle Class Sample } \\
\hline & Whites & Blacks & $(-)$ & Whites & Blacks & $(-)$ \\
\hline High school drop-out & .13 & .27 & $-.14 * *$ & .08 & .20 & $-.12 * *$ \\
\hline . & $(.33)$ & $(.44)$ & . & $(.28)$ & $(.40)$ & . \\
\hline High school graduate & .32 & .40 & $-.08 * *$ & .31 & .28 & .03 \\
\hline . & $(.47)$ & $(.49)$ & . & $(.46)$ & $(.45)$ & . \\
\hline Some post-secondary education & .55 & .33 & $.22 * *$ & .61 & .52 & $.09 *$ \\
\hline . & $(.50)$ & $(.47)$ & . & $(.49)$ & $(.50)$ & . \\
\hline Head ever reported job loss & .46 & .57 & $-.11 * *$ & .40 & .46 & -.06 \\
\hline . & $(.50)$ & $(.50)$ & . & $(.49)$ & $(.50)$ & . \\
\hline Gender (female) & .48 & .44 & .04 & .47 & .35 & $.12 * *$ \\
\hline . & $(.50)$ & $(.50)$ & . & $(.50)$ & $(.48)$ & . \\
\hline Firstborn & .41 & .29 & $.12 * *$ & .41 & .45 & -.03 \\
\hline . & $(.49)$ & $(.45)$ & . & $(.49)$ & $(.50)$ & . \\
\hline Number of siblings & 2.12 & 3.11 & $-.98 * *$ & 1.96 & 1.83 & .12 \\
\hline . & $(1.29)$ & $(2.31)$ & . & $(1.06)$ & $(.98)$ & . \\
\hline At least one college degree & .24 & .05 & $.19 * *$ & .27 & .16 & $.11^{* *}$ \\
\hline . & $(.42)$ & $(.22)$ & . & $(.44)$ & $(.37)$ & . \\
\hline Child born into two-parent household & .94 & .61 & $.33 * *$ & .98 & .92 & $.06^{* *}$ \\
\hline . & $(.24)$ & $(.49)$ & . & $(.15)$ & $(.28)$ & . \\
\hline
\end{tabular}




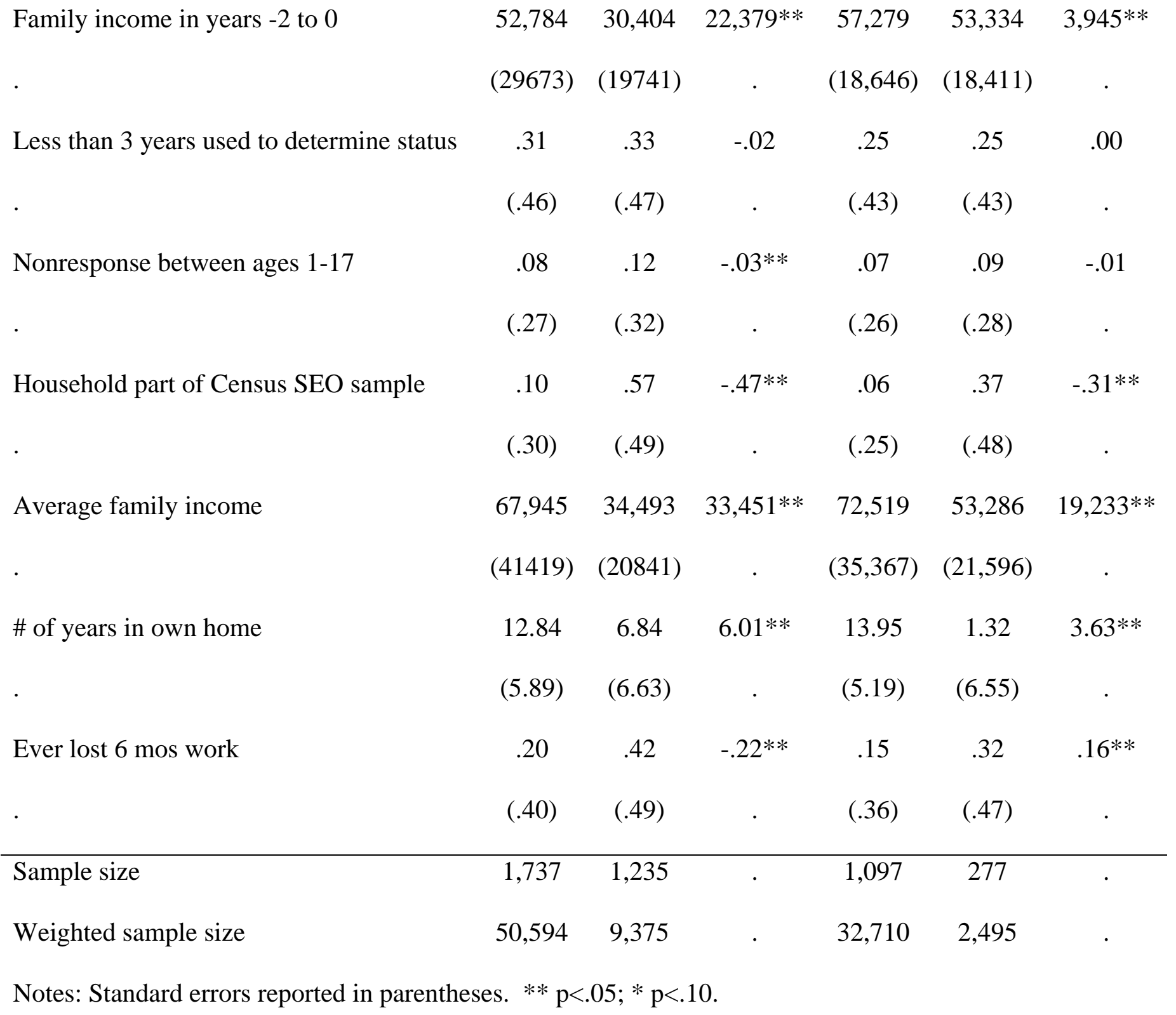


TABLE 2

LPM Coefficients of Job Loss and Class Status on College Attendance (Birth-Order, Region, Year, Non-Response Dummies Not Shown) $(\mathrm{N}=2,972)$

\begin{tabular}{|c|c|c|c|c|}
\hline & (1) & (2) & (3) & (4) \\
\hline Head ever reported job loss & $-.10 * *$ & $-.09 * *$ & $-.08 * *$ & $-.09 *$ \\
\hline . & $(.02)$ & $(.02)$ & $(.03)$ & $(.05)$ \\
\hline Head ever reported job loss*Black & . & . & -.06 & -.01 \\
\hline . & . & . & $(.06)$ & $(.07)$ \\
\hline Initial income 2-6 x FPL & . & $.09 * *$ & $.09 * *$ & $.09 *$ \\
\hline . & . & $(.04)$ & $(.04)$ & $(.05)$ \\
\hline Initial income 2-6 x FPL*Black & . & . & -.04 & .05 \\
\hline . & . & . & $(.07)$ & $(.09)$ \\
\hline Initial income $2-6$ x FPL*Lost job & . & . & . & -.01 \\
\hline . & . & . & . & $(.06)$ \\
\hline Initial income 2-6 x FPL*Lost job*Black & . & . & . & -.16 \\
\hline . & . & . & . & $(.12)$ \\
\hline Initial income $>6 \times \mathrm{FPL}$ & . & .10 & .10 & .01 \\
\hline . & . & $(.08)$ & $(.08)$ & $(.09)$ \\
\hline Initial income $>6 \times$ FPL*Black & . & . & -.11 & .01 \\
\hline . & . & . & $(.24)$ & $(.24)$ \\
\hline Initial income $>6 \times \mathrm{FPL} *$ Lost job & . & . & . & $.31 * *$ \\
\hline . & . & . & . & $(.09)$ \\
\hline
\end{tabular}




\begin{tabular}{|c|c|c|c|c|}
\hline Initial income $>6 \times$ FPL*Lost job*Black & . & . & . & .00 \\
\hline . & . & . & . & $(.00)$ \\
\hline \multirow[t]{2}{*}{ Black } & .01 & .01 & .06 & .03 \\
\hline & $(.04)$ & $(.04)$ & $(.06)$ & $(.06)$ \\
\hline \multirow[t]{2}{*}{ Gender (female) } & $.10^{* *}$ & $.10^{* *}$ & $.10 * *$ & $.10^{* *}$ \\
\hline & $(.02)$ & $(.02)$ & $(.02)$ & $(.02)$ \\
\hline \multirow[t]{2}{*}{ Number of siblings } & $-.02 *$ & -.01 & -.02 & -.01 \\
\hline & $(.01)$ & $(.01)$ & $(.01)$ & $(.01)$ \\
\hline \multirow[t]{2}{*}{ Child born into two-parent household } & .05 & .03 & .03 & .03 \\
\hline & $(.04)$ & $(.04)$ & $(.04)$ & $(.04)$ \\
\hline \multirow[t]{2}{*}{ At least one college degree } & $.29 * *$ & $.29 * *$ & $.29 * *$ & $.29 * *$ \\
\hline & $(.03)$ & $(.03)$ & $(.03)$ & $(.03)$ \\
\hline \multirow[t]{2}{*}{ Initial income } & $.02 * *$ & .01 & .01 & .01 \\
\hline & $(.01)$ & $(.01)$ & $(.01)$ & $(.01)$ \\
\hline \multirow[t]{2}{*}{ Nonresponse between ages 1-17 } & $-.14^{* *}$ & $-.14^{* *}$ & $-.14^{* *}$ & $-.14^{* *}$ \\
\hline & $(.04)$ & $(.04)$ & $(.04)$ & $(.04)$ \\
\hline \multirow[t]{2}{*}{ Household part of Census SEO sample } & $-.13^{* *}$ & $-.12 * *$ & $-.12 * *$ & $-.12 * *$ \\
\hline & $(.03)$ & $(.03)$ & $(.03)$ & $(.03)$ \\
\hline Constant & $.31 * *$ & $.28 * *$ & $.27 * *$ & $.27 * *$ \\
\hline . & $(.08)$ & $(.08)$ & $(.08)$ & $(.08)$ \\
\hline
\end{tabular}

Notes: Robust, clustered standard errors. ${ }^{* *} \mathrm{p}<.05 ;{ }^{*} \mathrm{p}<.10$ 
TABLE 3

LPM Coefficients of Job Loss on College Attendance in Middle-Class

Households (Birth-Order, Region, Year Dummies Not Shown) (N=1,374)

\begin{tabular}{|c|c|c|c|}
\hline & Whites & Blacks & $(-)$ \\
\hline \multirow{2}{*}{ Head ever reported job loss } & $-.09 * *$ & $-.25 * *$ & $.17 *$ \\
\hline & $(.03)$ & $(.09)$ & $(.08)$ \\
\hline \multirow[t]{2}{*}{ Gender (female) } & $.11^{* *}$ & $.14^{*}$ & -.03 \\
\hline & $(.03)$ & $(.07)$ & (.69) \\
\hline \multirow[t]{2}{*}{ Number of siblings } & $-.06 * *$ & -.02 & -.04 \\
\hline & $(.02)$ & $(.06)$ & $(.57)$ \\
\hline \multirow[t]{2}{*}{ Child born into two-parent household } & -.13 & $.31^{*}$ & $-.44 * *$ \\
\hline & $(.12)$ & $(.17)$ & $(.04)$ \\
\hline \multirow[t]{2}{*}{ At least one parent has college degree } & $.26 * *$ & $.44^{* *}$ & $-.18 *$ \\
\hline & $(.03)$ & $(.10)$ & $(.09)$ \\
\hline \multirow[t]{2}{*}{ Initial income } & $.02 * *$ & -.01 & .04 \\
\hline & $(.01)$ & $(.03)$ & $(.21)$ \\
\hline \multirow[t]{2}{*}{ Nonresponse between ages 1-17 } & $-.18 * *$ & .00 & -.18 \\
\hline & $(.06)$ & $(.13)$ & $(.21)$ \\
\hline \multirow[t]{2}{*}{ Household part of Census SEO sample } & $-.20 * *$ & .14 & $-.34 * *$ \\
\hline & $(.06)$ & $(.09)$ & $(.00)$ \\
\hline Race Dummy & .67 & .28 & . \\
\hline . & $(.17)$ & $(.34)$ & . \\
\hline
\end{tabular}

Robust, clustered standard errors. Differences results of post-hoc F-tests. ${ }^{* *} \mathrm{p}<.05 ;{ }^{*} \mathrm{p}<.10$ 


\section{TABLE 4}

Linear Probability Regression Coefficients of Job Loss and Childhood Conditions on College Attendance

(Birth-Order, Region, Year Dummies Not Shown) $(\mathrm{N}=1,374)$

\begin{tabular}{|c|c|c|c|c|c|c|c|c|c|}
\hline & Ave & rage Ince & e \& & & & & Income & Home & nershin \\
\hline & Ho & ne Owne & hip & & employr & & $\&$ & Inemplo & ent \\
\hline & Whites & Blacks & $(-)$ & Whites & Blacks & $(-)$ & Whites & Blacks & $(-)$ \\
\hline Head ever reported job loss & $-.07 * *$ & $-.21 * *$ & .14 & $-.07 *$ & $-.14^{*}$ & .07 & -.05 & -.13 & .08 \\
\hline . & $(.03)$ & $(.09)$ & $(.14)$ & $(.04)$ & $(.08)$ & $(.42)$ & $(.04)$ & $(.08)$ & $(.37)$ \\
\hline Average family income & $.02 * *$ & $.05 * *$ & -.03 & . & . & . & $.02 * *$ & $.03 *$ & -.02 \\
\hline . & $(.01)$ & $(.02)$ & $(.11)$ & . & . & . & $(.01)$ & $(.02)$ & (.39) \\
\hline \# of years in own home & $.01 *$ & -.01 & $.02 * *$ & . & . & . & $.01 *$ & -.01 & .01 \\
\hline . & $(.00)$ & $(.01)$ & $(.04)$ & . & . & . & $(.00)$ & $(.01)$ & $(.10)$ \\
\hline Ever lost 6 mos work & . & . & . & -.08 & $-.26 * *$ & $.18^{*}$ & -.06 & $-.20 * *$ & .14 \\
\hline . & . & . & . & $(.05)$ & $(.09)$ & $(.08)$ & $(.05)$ & $(.09)$ & (.18) \\
\hline At least one college degree & $.23 * *$ & $.38 * *$ & -.15 & $.26 * *$ & $.41 * *$ & -.15 & $.23 * *$ & $.38 * *$ & -.15 \\
\hline . & $(.04)$ & $(.11)$ & $(.18)$ & $(.03)$ & $(.10)$ & $(.14)$ & $(.04)$ & $(.11)$ & $(.18)$ \\
\hline
\end{tabular}




\begin{tabular}{|c|c|c|c|c|c|c|c|c|c|}
\hline \multirow[t]{2}{*}{ Gender (female) } & $.11^{* *}$ & $.13^{*}$ & -.02 & $.11^{* *}$ & .13 & -.02 & $.11^{* *}$ & .12 & -.01 \\
\hline & $(.03)$ & $(.07)$ & $(.83)$ & $(.03)$ & $(.08)$ & $(.84)$ & $(.03)$ & $(.08)$ & $(.91)$ \\
\hline \multirow[t]{2}{*}{ Number of siblings } & $-.06 * *$ & -.02 & -.04 & $-.06 * *$ & -.02 & -.04 & $-.06 * *$ & -.02 & -.04 \\
\hline & $(.02)$ & $(.06)$ & $(.57)$ & $(.02)$ & $(.07)$ & $(.55)$ & $(.02)$ & $(.07)$ & $(.54)$ \\
\hline \multirow[t]{2}{*}{ Child born into two-parent household } & -.15 & $.30 *$ & $-.46^{* *}$ & -.12 & $.37 * *$ & $-.50 * *$ & -.15 & $.36^{* *}$ & $-.51^{* *}$ \\
\hline & $(.12)$ & $(.18)$ & $(.03)$ & $(.12)$ & $(.16)$ & $(.01)$ & $(.12)$ & $(.18)$ & $(.01)$ \\
\hline \multirow[t]{2}{*}{ Initial income } & .01 & -.03 & .04 & $.02 * *$ & -.02 & .04 & .01 & -.03 & .03 \\
\hline & $(.01)$ & $(.03)$ & $(.20)$ & $(.01)$ & $(.03)$ & $(.16)$ & $(.01)$ & $(.03)$ & $(.21)$ \\
\hline \multirow[t]{2}{*}{ Nonresponse between ages 1-16 } & $-.12 * *$ & -.04 & -.08 & $-.17 * *$ & -.03 & -.14 & $-.12 * *$ & -.05 & -.07 \\
\hline & $(.06)$ & $(.13)$ & $(.56)$ & $(.06)$ & $(.13)$ & $(.30)$ & $(.06)$ & $(.12)$ & $(.61)$ \\
\hline \multirow[t]{2}{*}{ Household part of Census SEO sample } & $-.19 * *$ & .12 & $-.31 * *$ & $-.19 * *$ & .13 & $-.33 * *$ & $-.19 * *$ & .12 & $-.31^{* *}$ \\
\hline & $(.06)$ & $(.10)$ & $(.01)$ & $(.06)$ & $(.09)$ & $(.00)$ & $(.06)$ & $(.09)$ & $(.00)$ \\
\hline \multirow[t]{2}{*}{ Race Dummy } & .54 & .29 & . & .67 & .42 & . & .55 & .40 & . \\
\hline & $(.17)$ & $(.34)$ & . & $(.17)$ & $(.32)$ & . & $(.17)$ & $(.33)$ & . \\
\hline
\end{tabular}

Notes: Robust, clustered standard errors reported in parentheses. Differences results of post-hoc F-tests. ${ }^{* *} \mathrm{p}<.05$; ${ }^{*} \mathrm{p}<.10$ 
Figure 1: Initial Income (in \$1,000) by Decile

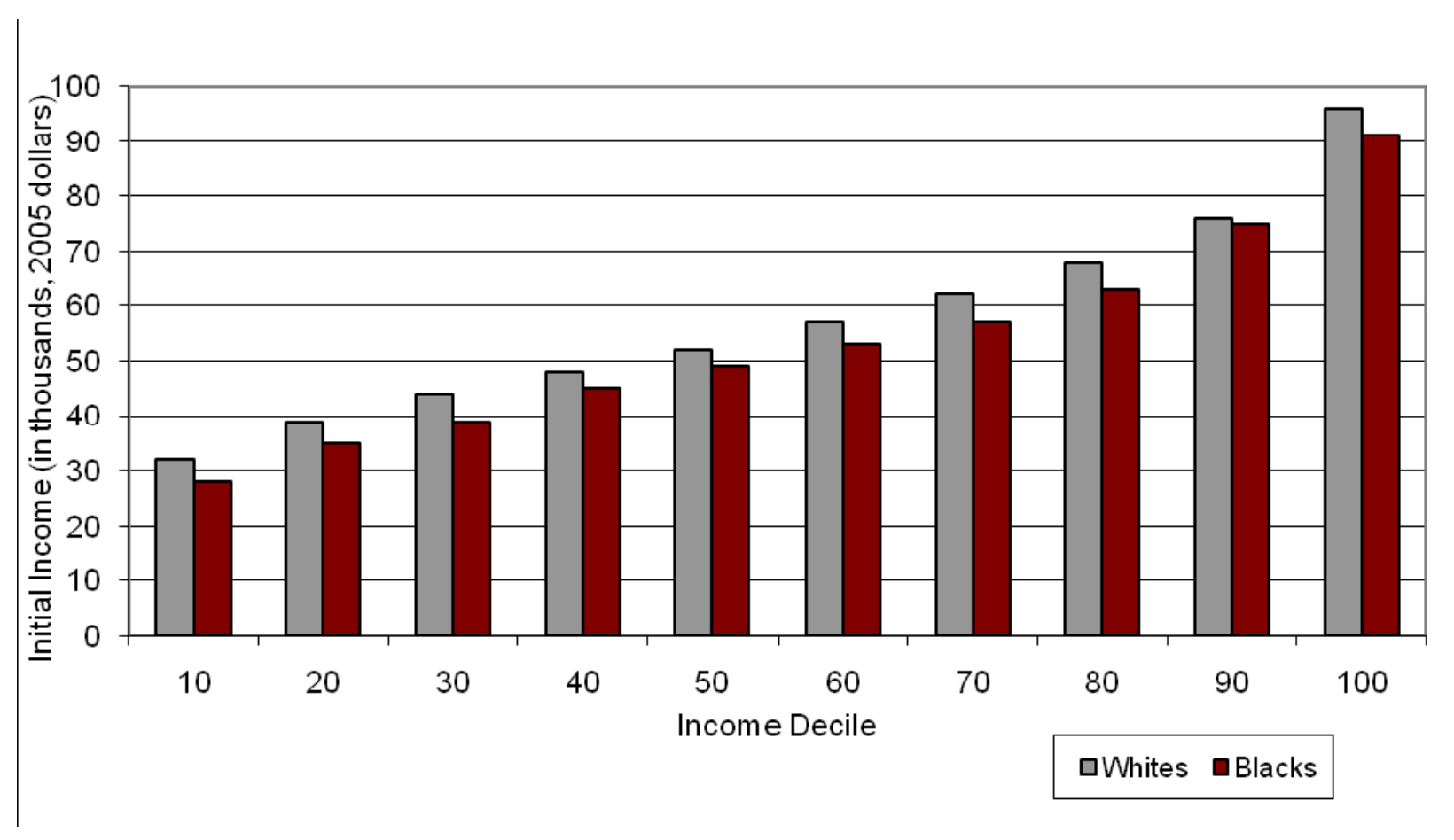

Figure 2: Average Annual Income (in \$1,000) at Each Age in Childhood

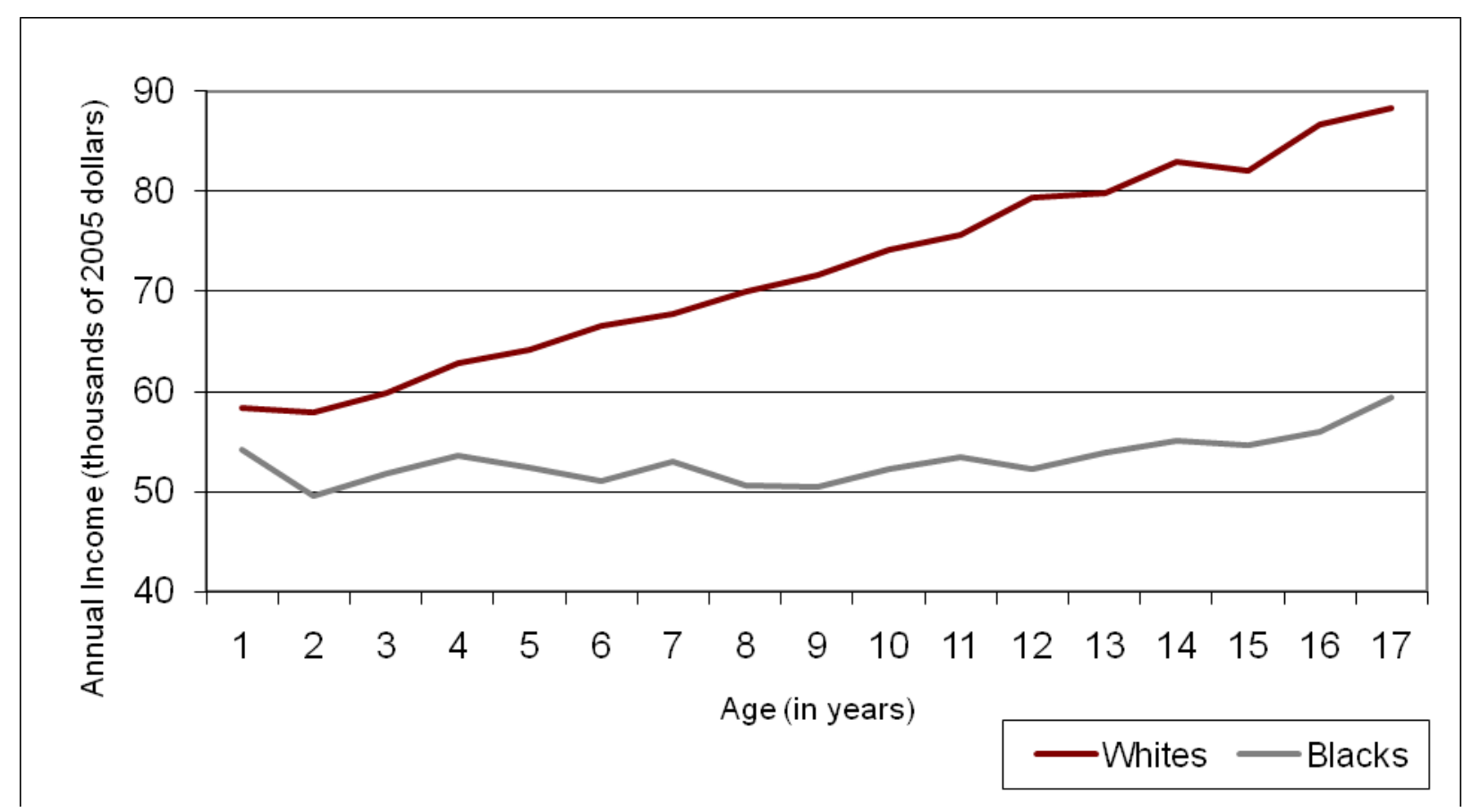

